\title{
PERANAN SEKRETARIS DALAM MENYIAPKAN PERJALANAN DINAS FUNGSI TURNAROUND REFINERY PADA PT PERTAMINA (PERSERO)
}

\author{
Oleh: Tri Agus Siswanto,S.Pd,MM \\ Dosen Sekretari Universitas Pamulang \\ dan \\ Sri Eti Septini \\ Mahasiswi Sekretari Universitas Pamulang
}

\begin{abstract}
Astrak
Seorang Sekretaris dibutuhkan oleh setiap organisasi untuk membantu dalam bidang organisasi dan kedinasan, dengan kata lain melaksanakan fungsi perkantoran dan manajerial dengan baik. Agar perjalanan dinas dapat berjalan secara efektif, maka perlu dilakukan penjadwalan dan pengaturan pada perjalanan dinas tersebut, sehingga pekerjaan tidak ada terbengkalai hanya karena kesalahan dalam menyusun jadwal atau tidak adanya jadwal yang digunakan sebagai acuan pelaksanaan perjalanan dinas.
\end{abstract}

\section{A. Latar Belakang}

Dalam mengelola perjalanan dinas seorang Sekretaris diharapkan agar selalu siap untuk mengatur segala sesuatu yang diharapkan. Hal - hal yang biasanya harus dilakukan seorang Sekretaris dalam menangani perjalanan dinas pimpinan antara lain: Pertama, mengatur tujuan perjalanan dinas, tanggal keberangkatan, dan transportasi yang digunakan. Kedua, mengurus akomodasi, konfirmasi tiket, pembuatan jadwal perjalanan dinas. Ketiga, mempersiapkan dokumen surat yang diperlukan.

\section{B. Identifikasi Masalah}

Berdasarkan latar belakang masalah yang terjadi, maka penulis mengidentifikasi masalah yaitu:

1. Tujuan dari Perjalanan Dinas tersebut

2. Apa saja yang perlu dipersiapkan untuk mendukung kesiapan perjalanan dinas

3. Trasnportasi apa saja yang akan dipergunakan dalam perjalanan dinas

4. Bagaimana pembuatan laporan perjalanan dinas 


\section{Pembatasan Masalah}

Pada dasarnya tugas sekretaris meliputi tugas rutin, tugas khusus, tugas istimewa, tugas resepsionis, tugas keuangan, tugas social, tugas insidential, dan juga tugas kreatif.

\section{Rumusan Masalah}

Berdasarkan latar belakang, identifikasi masalah, pembatasan masalah maka penulis perlu merumuskan masalahnya yaitu:

- Bagaimana peranan sekretaris dalam menyiapkan perjalanan dinas?

\section{E. Tujuan dan Manfaat Laporan}

1. Tujuan

Untuk mengetahui mengetahui peranan Sekretaris dalam mempersiapkan perjalanan dinas pada dinas Fungsi Turnaround Refinery pada PT Pertamina (Persero).

2. Manfaat penulisan

Bagi Penulis :

a) Sebagai persyaratan untuk memperoleh gelar Ahli Madya Fakultas Ekonomi Program Studi Sekretari.

b) Mempraktekan ilmu kesekretariatan yang sudah didapat dibangku kuliah untuk diaplikasikan ke dalam dunia kerja yang sesungguhnya.

c) Mengembangkan kemampuan dan ketrampilan dalam penanganan perjalanan dinas.

3. Bagi Institusi :

a) Meningkatkan produktivitas Sekretaris dan Perusahaan.

b) Mempermudah sekretaris dalam mempersiapkan penyelengaraan perjalanan dinas. 


\section{F. Pembahasan}

\section{Pengertian Sekretaris}

Kata Sekretaris berasal dari bahasa Latin sectrum yang berarti rahasia. Kata ini juga dikenal dalam bahasa Belanda secretaries, dan dalam bahasa Inggrisnya secretary. Dari pengertian ini seorang sekretaris dituntut mampu menyimpan rahasia dalam melaksanakan pekerjaannya (menurut Ursula Ernawati).

Berikut ini pengertian Sekretaris yang penulis ambil dari berbagai sumber:

a. Menurut Dr. Durotul Yatimah, MpD

Sekretaris adalah : Seseorang yang dapat dipercaya oleh pimpinan dalam membantu memperlancar pekerjaan, terutama untuk penyelenggaraan kegiatan administrastif yang menunjang kegiatan manajerial Pimpinan atau kegiatan operational Perusahaan, serta membantu Pimpinan dalam membina tata hubungan (komunikasi) dengan bawahan maupun pihak lain yang berkepentingan dengan Perusahaan.

b. Menurut DR. Ny. Siwi Kadarmo

Sekretaris adalah : mengenai seseorang pembantu dari seorang Pimpinan untuk menyelenggarakan bagian - bagian kecil dari tugas pekerjaan Pimpinan, dan yang memiliki kedudukan yang lebih bertanggungjawab daripada seorang stenographer. Bahkan dia dapat berkedudukan sebagai Pimpinan dalam unit pekerjaannya. Meskipun macam pekerjaan itu pada hakekatnya adalah pekerjaan kantor, tetapi perlu ditekankan disini bahwa pekerjaan kantor berarti tugas-tugas di kantor yang bermutu tinggi.

\section{c. Menurut ASEKMA DON BOSCO}

Sekretaris adalah orang yang membantu Pimpinan dalam melaksanakan tugas perkantoran yang timbul sebagai akibat dari tugas kepemimpinan. Jadi Sekretaris membantu Pimpinan agar Pimpinan yang dilayani dapat melaksanakan tugasnya dengan baik.

d. Menurut Wikipedia

Sekretaris adalah sebuah profesi administrastif yang bersifat asisten atau mendukung. Gelar ini merujuk kepada sebuah pekerjaan kantor yang tugasnya ialah melaksanakan pekerjaan rutin, tugas - tugas 3rofessional3e atau tugas-tugas pribadi dari atasannya. 
e. Menurut http://www. organisasi.org/1970/01/ manajemen-sekretarispengertian-tugas-fungsi-peran-syarat-tata-kerja-dll.html.

Sekretaris mempunyai arti rahasia atau orang yang memegang rahasia. Pengertian umum sekretaris mempunyai arti atau sama dengan penulis (notulen), walaupun sebenarnya pengertian penulis di sini tidak sama dengan penulis cerita pendek ataupun novel.

f. Menurut Rumsari Hadi Sumarto dan Lukas Dwiantoro).

Pekerjaan sekretaris pada dasarkan merupakan perpanjangan dari pekerjaan pimpinan, agar pimpinan dapat mengkonsentrasikan diri untuk melakukan tugas manajerial dalam suatu organisasi atau perusahaan

\section{Tugas - tugas Sekretaris}

Tugas sekretaris pada dasarnya mencakup 2 (dua) hal. Pertama, tugas yang berhubungan dengan tugas kesekretarisannya. Kedua, yang sekaligus merupakan tugas utama dari seorang sekretaris yaitu membantu pimpinan agar pimpinan dapat bekerja secara optimal, berhasil guna, berdaya guna, dan lebih professional. Tugas - tugas sekretaris profesional dibagi sebagai berikut :

1. Menurut wewenangnya

a. Tugas Rutin, yaitu tugas - tugas yang profesional setiap hari dihadapi dan harus dikerjakan tanpa menunggu perintah atau instruksi khusus dari pimpinan, yang harus dilakukan oleh sekretaris tanpa membuang waktu dan tanpa memerlukan usaha-usaha khusus. Selama tugas-tugas tersebut menjadi tanggung jawab sekretaris.

b. Tugas Instruksi, Tugas-tugas yang tidak setiap hari dihadapi dan hanya dikerjakan bila ada perintah dari pimpinan. Berkaitan dengan kekhususan dari tugas tersebut, untuk kelancaran pekerjaan yang dibebankan kepadanya, seorang sekretaris harus memperhatikan hal-hal berikut : konsentrasi penuh, mendengarkan dengan sungguh-sunguh, bertanya hal yang kurang jelas, mencatat hal-hal penting dan meningkatkan wawasan.

c. Tugas Kreatif, tugas yang dikerjakan oleh sekretaris atas dasar professional. Tugas kreatif ini tidak terdapat dalam uraian tugas. Tugas tersebut dilakukan guna meringankan beban pekerjaan atau menciptakan efisiensi dan efektivitas kerja.

2. Menurut jenis tugasnya 
a. Tugas Administrasi/Perkantoran, berhubungan dengan tulis-menulis, dokumentasi dan pengetikan, antara lain :

1) Membuat konsep surat

2) Mempersiapkan meja kerja pimpinan, mengambil dan menyalin dikte dari pimpinan

3) Filing

4) Menangani surat, dan lain sebagainya

b. Tugas Resepsionis, berhubungan dengan pekerjaan komunikasi, antara lain :

1) Menerima telepon

2) Mencatat pesan - pesan lewat telepon

3) Menerima dan melayani tamu yang akan bertemu pimpinan

4) Menyusun jadwal perjanjian pimpinan, dan lain sebagainya

c. Tugas Keuangan, antara lain :

1) Menangani urusan keuangan pimpinan

2) Menangani petty cash, dan lain sebagainya

d. Tugas Sosial, antara lain :

1) Mengatur rumah tangga kantor (perlengkapan kantor, alat tulis)

2) Mengirimkan ucapan selamat atau bela sungkawa kepada relasi kepada relasi

3) Mempersiapkan resepsi, dan lain sebagainya

e. Tugas Insidental, antara lain :

1) Mempersiapkan rapat

2) Mempersiapkan pidato, presentasi

3) Mempersiapkan perjalanan dinas pimpinan, dan lain sebagainya

\section{Pengertian Perjalanan Dinas}

Seorang sekretaris yang handal, umumnya dipercayai pimpinannya untuk mengatur perjalanan dinas pimpinan

Sehubungan dengan perjalanan dinas tersebut, Pimpinan tidak perlu mempersiapkan sendiri segala sesuatunya, karena Sekretaris memiliki tugas untuk mengurus kepergian Pimpinan mulai keberangkatan sampai kepulangannya. Bahkan sering pula Sekretaris diminta untuk membuat laporan perjalanan dinas setelah dilakukan oleh Pimpinan. 
Perjalanan dinas para Pimpinan biasanya dilakukan karena berbagai kepentingan.Tujuan tersebut harus ditanyakan terlebih dahulu kepada pimpinan agar sekretaris dapat mempersiapkan dokumen yang harus dibawa sesuai tujuan perjalanan dinas pimpinan.

\section{Macam-macam Perjalanan Dinas}

Perjalanan dinas pimpinan dapat dibedakan berdasarkan klasifikasi tujuan, sarana transportasi yang digunakan, lama waktunya, dan wilayah kota atau Negara tujuan. Berdasarkan sarana transportasi yang digunakan, perjalanan dinas pimpinan dapat dibedakan menjadi tiga macam, yang membawa konsekuensi terhadap tugas yang dilakukan sekretaris, yaitu sebagai berikut :

\section{Perjalanan Dinas Lewat Udara}

Perjalanan dinas pimpinan lewat udara dengan menggunakan fasilitas pesawat udara hendaknya benar-benar dipertimbangkan tingkat efektivitas dan efisiensinya. Mendesak atau tidaknya waktu dan urusan yang diperlukan untuk menyelesaikan masalah serta kondisi keuangan perusahaan hendaknya menjadi pertimbangan untuk memutuskan penggunaan alat transportasi pesawat udara.

2. Perjalanan Dinas Lewat Darat

Perjalanan dinas lewat darat bisa dilakukan dengan menggunakan mobil perusahan, travel, bus atau kereta api. Perjalanan dinas lewat darat tidak memerlukan dokumen khusus sehingga sekretaris hanya melakukan persiapan berupa pemesanan dan pembelian tiket dan dokumen-dokumen yang berkaitan langsung dengan tujuan pokok perjalanan dinas. Namun apabila pimpinan melakukan perjalanan dinas lebih dari satu hari, sekretaris harus mempersiapkan akomodasi selama ditempat tujuan, antara lain hotel, sarana transportasi antar jemput dari hotel ke tempat tujuan, dan sebaliknya.

3. Perjalanan Dinas Lewat Laut

Perjalanan dinas lewat laut dapat memanfaatkan berbagai fasilitas pelayanan yang ditawarkan oleh beberapa perusahaan armada laut. Adapun persiapan dan tugas yang harus dilakukan sekretaris adalah mempersiapkan dokumen perjalaan dinas dengan melakukan pemesanan dan pembelian tiket armada laut untuk perjalanan dinas dalam negeri. Adapun untuk perjalanan dinas ke luar negeri, sekretaris harus 
menambahkan beberapa dokumen seperti paspor, visa dan lain-lain. Sekretaris juga harus mempersiapkan akomodasi selama ditempat tujuan dan dokumen yang terkait langsung dengan tujuan pokok perjalanan dinas.

\section{Perencanaan Perjalanan Dinas}

Untuk menyusun rencana perjalanan dinas pimpinan, sekretaris dapat bekerja sendiri, tetapi tetap melakukan konfirmasi dari pimpinan tentang segala sesuatu yang harus dipersiapkan. Hal ini perlu dilakukan karena biasanya pimpinan memiliki keinginan, pemikiran dan rencana tertentu berkaitan dengan perjalanan dinasnya.

Tahap awal perencanaan perjalanan dinas pimpinan adalah mengidentifikasi beberapa informasi, yaitu:

- Tujuan Perjalanan Dinas Pimpinan

- Waktu Pelaksanaan Kegiatan Pokok Perjalanan Dinas

- Acara Lain diluar Perjalanan Dinas

- Acara setelah Kegiatan Pokok

\section{Persiapan Perjalanan Dinas}

Apabila sudah mendapat rencana yang pasti untuk perjalanan pimpinan, tugas sekretaris selanjutnya adalah melakukan persiapan, yang mencakup :

- Persiapan Transportasi

- Persiapan Akomodasi

- Persiapan Jadwal Perjalanan

Tabel 2-1. Contoh Jadwal Kegiatan Perjalanan Dinas

Itinerary Mr......

PT

\begin{tabular}{|l|l|l|l|}
\hline Date & Time & Schedule & Remaks \\
\hline & & & \\
\hline
\end{tabular}


- Persiapan Keuangan

Tabel 2-2. Contoh Permintaan Uang Muka Kerja

\section{Permintaan Uang Muka}

Nama.

Tujuan \& Tanggal

\begin{tabular}{|c|l|c|c|c|}
\hline No & \multicolumn{1}{|c|}{ Keterangan } & US\$ & WON & Rp \\
\hline 1. & $\begin{array}{l}\text { Fiskal \& Airport Tax : } \\
\text { Fiskal } \\
\text { Airport Tax }\end{array}$ & & & \\
\hline 2. & Hotel & & & \\
\hline 3. & Meals \& Entertaintment & & & \\
\hline 4. & Transportation & & & \\
\hline 5. & Uang Saku & & & \\
\hline & Total Pemakaian Uang & & & \\
\hline Dirupiahkan & & & \\
\hline \multicolumn{2}{|l|}{ Biaya Yang Telah Dikeluarkan } & & & \\
\hline \multicolumn{2}{l}{ Perkiraan } & & & \\
\hline \multicolumn{2}{|l}{ Permintaan Uang Muka } & & & \\
\hline
\end{tabular}

\section{Dokumen Perjalanan Dinas}

Siapkan dokumen yang akan dibawa oleh pimpinan dan pastikan sehari sebelum keberangkatan bersama dengan itinerary, tiket dan voucher hotel, dan uang yang harus diberikan kepada pimpinan.

Tabel 2-3. Contoh Check List

DAFTAR PERIKSA PERJALANAN

TUJUAN............................

TANGGAL

\section{Dokumen}

Paspor \& Exit Permit

Visa

Tiket 


\begin{tabular}{|l|}
\hline Voucher Hotel \\
\hline Peralatan \\
Laptop \\
Itinerary \\
USB \\
Memo Pad + Alat Tulis \\
Buku Alamat \& Telepon \\
Kartu Nama \\
Peta \\
\hline
\end{tabular}

Apabila perjalanan dinas lewat udara dan dilakukan antar Negara, maka dokumen - dokumen yang harus dipersiapkan sebagai berikut :
a. Surat Tugas
b. Passport
c. Visa
d. Fiskal
e. Tiket Pesawat Udara
f. Voucher Hotel
g. Sertifikat Kesehatan
h. Dokumen - dokumen pendukung lainnya

\section{Peraturan Perjalanan Dinas}

Disetiap perusahaan memiliki peraturan yang mengatur perjalanan untuk pimpinan dan karyawannya. Beberapa perusahaan memiliki bagian yang mengurusi segala keperluan staf yang akan melakukan perjalanan dinas. Disini tugas sekretaris cukup mengisi formulir yang telah tersedia dan menyampaikan ke bagian tersebut. Ada juga yang menunjuk biro perjalanan tertentu, namun jika tidak ada maka sekretaris harus menyiapkan segala sesuatunya.

\section{Laporan Perjalanan Dinas}

Sepulang pimpinan dari perjalanannya, salah satu tugas sekretaris adalah membuatkan laporan pertanggungjawaban keuangan. Jangan lupa mintakan semua tanda bukti atau bon. Lihat lagi aturannya - aturannya, apa saja yang 9rof diklaim 
dan sampai harga berapa, apakah pimpinan harus mengembalikan uang kelebihannya atau perusahaan yang masih harus membayar kekurangannya.

Tabel 2-4. Contoh Pertanggungjawaban Uang Muka

Pertanggungjawaban Uang Muka

Nama..........................

Tujuan \& Tanggal.

\begin{tabular}{|c|l|l|c|c|}
\hline No & \multicolumn{1}{|c|}{ Keterangan } & US\$ & WON & Rp \\
\hline 1. & $\begin{array}{l}\text { Fiskal \& Airport Tax : } \\
\text { Fiskal } \\
\text { Airport Tax }\end{array}$ & & & \\
\hline 2. & Hotel & & & \\
\hline 3. & Meals \& Entertaintment & & & \\
\hline 4. & Transportation & & & \\
\hline 5. & UangSaku & & & \\
\hline \multicolumn{2}{|l|}{ Total Pemakaian Uang } & & & \\
\hline Dirupiahkan & & & \\
\hline Biaya Yang Telah Dikeluarkan & & & \\
\hline Permintaan UangMuka & & & \\
\hline Jadi Kekurangan & & & \\
\hline
\end{tabular}

Walaupun pimpinan tidak berada ditempat, bukan berarti sekretaris bebas dari tugas - tugasnya. Sekretaris harus bersikap professional, tetap menjalankan tugasnya dengan cermat, teliti dan rapi. Oleh karena itu :

1) Lakukan pekerjaan rutin seperti biasa

2) Membuat laporan - laporan

3) Adakalanya pimpinan menelpon secara teratur. Beritahu telepon, tamu dan surat surat penting yang masuk serta kejadian atau perubahan - perubahan yang terjadi dikantor

4) Biasanya sekretaris tahu dimana harus menghubungi pimpinan di saat - saat mendesak. Akan tetapi, harus tetap bijaksana dan membuat pimpinan menjadi tidak terganggu. 


\section{G. Pembahasan Dan Hasil}

\section{Sekilas Gambaran}

Tonggak-tonggak sejarah berdirinya PT Pertamina (Persero) sebagai Perusahaan BUMN sejak tahun 1957 hingga berubah status 11rofe menjadi Perusahaan Perseroan Terbatas (Persero)

\section{- Masa Kemerdekaan}

Pada 1950-an, ketika penyelenggaraan 11rofes mulai berjalan normal seusai perang mempertahankan kemerdekaan, Pemerintah Republik Indonesia mulai menginventarisasi sumber-sumber pendapatan 11rofes, di antaranya dari minyak dan gas. Namun saat itu, pengelolaan 11rofes-ladang minyak peninggalan Belanda terlihat tidak terkendali dan penuh dengan sengketa. Di Sumatera Utara misalnya, banyak perusahaan-perusahaan kecil saling berebut untuk menguasai 11rofes-ladang tersebut.

\section{- Integrasi Pengelolaan Migas Indonesia}

Pada tahun 1960, PT PERMINA direstrukturisasi menjadi PN PERMINA sebagai tindak lanjut dari kebijakan Pemerintah, bahwa pihak yang berhak melakukan eksplorasi minyak dan gas di Indonesia adalah 11 rofes.

Melalui satu Peraturan Pemerintah yang dikeluarkan Presiden pada 20 Agustus 1968, PN PERMINA yang bergerak di bidang produksi digabung dengan PN PERTAMIN yang bergerak di bidang pemasaran guna menyatukan tenaga, modal dan sumber daya yang kala itu sangat terbatas. Perusahaan gabungan tersebut dinamakan PN Pertambangan Minyak dan Gas Bumi Nasional (Pertamina).

\section{- Tonggak Migas Indonesia}

Untuk memperkokoh perusahaan yang masih muda ini, Pemerintah menerbitkan Undang-Undang No. 8 tahun 1971, dimana di dalamnya mengatur peran Pertamina sebagai satu-satunya perusahaan milik negara yang ditugaskan melaksanakan pengusahaan migas mulai dari mengelola dan menghasilkan migas dari ladang-ladang minyak di seluruh wilayah Indonesia, mengolahnya menjadi berbagai produk dan menyediakan serta melayani kebutuhan bahan bakar minyak \& gas di seluruh Indonesia.

\section{- Dinamika Migas Indonesia}


Seiring dengan waktu, menghadapi dinamika perubahan di 12rofessi minyak dan gas nasional maupun global, Pemerintah menerapkan Undang-Undang No. 22/2001. Paska penerapan tersebut, Pertamina memiliki kedudukan yang sama dengan perusahaan minyak lainnya. Penyelenggaraan kegiatan bisnis PSO tersebut akan diserahkan kepada mekanisme persaingan usaha yang wajar, sehat, dan transparan dengan penetapan harga sesuai yang berlaku di pasar.

Pada 17 September 2003 Pertamina berubah bentuk menjadi PT Pertamina (Persero) berdasarkan PP No. 31/2003. Undang-Undang tersebut antara lain juga mengharuskan pemisahan antara kegiatan usaha migas di sisi hilir dan hulu.

\section{- Masa Transformasi}

Pada 10 Desember 2005, sebagai bagian dari upaya menghadapi persaingan bisnis, PT Pertamina mengubah logo dari 12rofess kuda laut menjadi anak panah dengan tiga warna dasar hijau-biru-merah. Logo tersebut menunjukkan 12rofes kedinamisan serta mengisyaratkan wawasan lingkungan yang diterapkan dalam aktivitas usaha Perseroan.

Selanjutnya pada 20 Juli 2006, PT Pertamina mencanangkan program transformasi perusahaan dengan 2 tema besar yakni fundamental dan bisnis. Untuk lebih memantapkan program transformasi itu, pada 10 Desember 2007 PT Pertamina mengubah visi perusahaan yaitu, "Menjadi Perusahaan Minyak Nasional Kelas Dunia”. Menyikapi perkembangan global yang berlaku, Pertamina mengupayakan perluasan bidang usaha dari minyak dan gas menuju 12rofess pengembangan 12rofes baru dan terbarukan, berlandaskan hal tersebut di tahun 2011 Pertamina menetapkan visi baru perusahaannya yaitu, "Menjadi Perusahaan Energi Nasional Kelas Dunia”.

\section{- Visi dan Misi}

Visi : Menjadi Perusahaan Energi Nasional Kelas Dunia. Misi: Menjalankan usaha minyak, gas, serta 12rofes baru dan terbarukan secara terintegrasi, berdasarkan prinsip-prinsip komersial yang kuat.

Misi Perseroan menjalankan usaha inti minyak, gas, bahan bakar nabati serta kegiatan pengembangan, eksplorasi, produksi dan niaga 12rofes baru dan terbarukan (new and renewable energy) secara terintegrasi.

\section{- Tata Nilai Perusahaan}

Pertamina menetapkan enam tata nilai perusahaan yang dapat menjadi pedoman bagi seluruh karyawan dalam menjalankan perusahaan, sebagai berikut : 
1. CLEAN (BERSIH)

2. COMPETITIVE (KOMPETITIF)

3. CONFIDENT (PERCAYA DIRI)

4. CUSTOMER FOCUS (FOKUS PADA PELANGGAN)

5. COMMERCIAL (KOMERSIAL)

6. CAPABLE (BERKEMAMPUAN)

- Jajaran Direksi PT Pertamina (Persero)

Berikut adalah jajaran manajemen yang berada pada PT Pertamina (Persero) yang terdiri dari Dewan Direksi dan Dewan Komisaris :

Tabel 3-1. Jajaran Direksi PT PETAMINA (PERSERO)

\begin{tabular}{|r|l|l|}
\hline No & \multicolumn{1}{|c|}{ Direksi } & Komisaris \\
\hline \hline 1 & Direktur Utama & Komisaris Utama \\
\hline \hline 2 & $\begin{array}{l}\text { Direktur Perencanaan Investasi } \\
\text { dan Manajemen Resiko }\end{array}$ & Komisaris \\
\hline \hline 3 & Direktur Hulu & Komisaris \\
\hline \hline 4 & Direktur Pengolahan & Komisaris \\
\hline \hline 5 & Direktur Pemasaran dan Niaga & Komisaris \\
\hline \hline 6 & Direktur Gas & Komisaris \\
\hline \hline 7 & Direktur Umum & \\
\hline \hline 8 & Direktur Sumber Daya Manusia & \\
\hline \hline 9 & Direktur Keuangan \\
\hline
\end{tabular}

2. Struktur Organisasi Turnaround Refinery

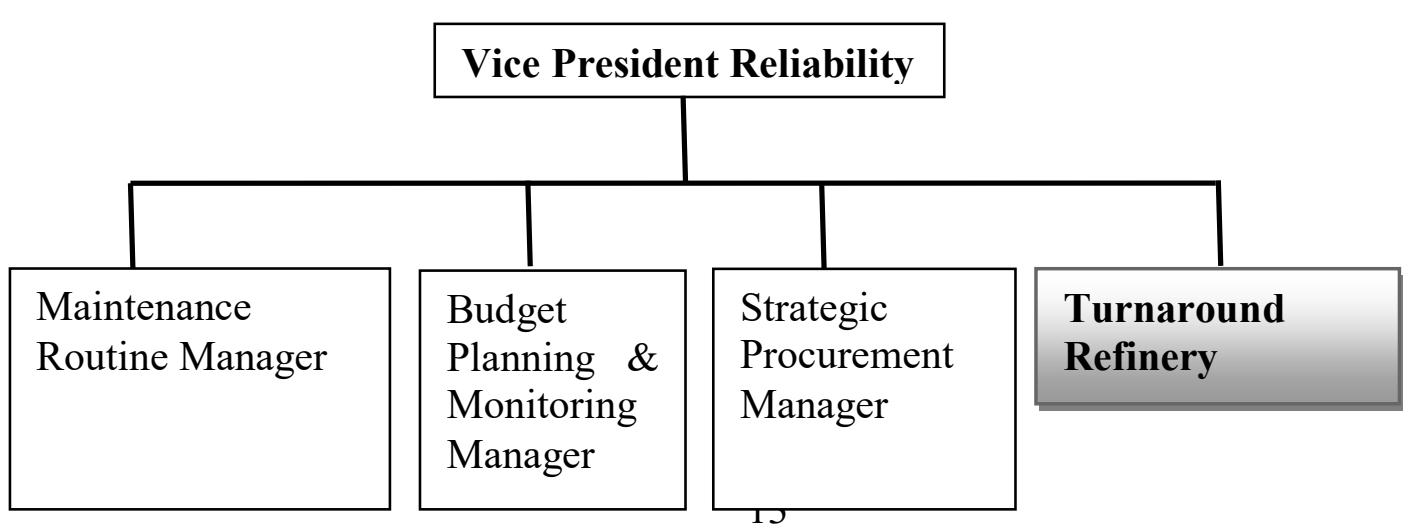




\section{Gambar 3-1. Struktur Organisasi Turnaround Refinery}

\section{Job Description Turnaround Refinery Manager}

Mengarahkan, memonitor dan mengevaluasi kebijakan dan sistem tata kerja terkait turnaround/overhaul, strategi kehandalan kilang, rencana kehandalan kilang, assessment kondisi peralatan saat turnaround/overhaul, dan langkah tindak lanjut kehandalan kilang untuk seluruh Refinery Unit di Pertamina.

\section{Pembahasan dan Hasil Praktek Kerja Lapangan}

\section{Tempat dan Waktu Pelaksanaan Praktek Kerja Lapangan}

Pelaksanaan praktek kerja lapangan bertempat di PT Pertamina (Persero) fungsi Turnaround Refinery. Pelaksanaan Praktek Kerja Lapangan berlangsung mulai tanggal 30 Mei s/d 9 Agustus 2014.

\section{Pekerjaan Pengelolaan Perjalanan Dinas}

Perjalanan dinas yang dilakukan pada PT Pertamina (Persero), memiliki beberapa jenis, diantaranya :

a) Perjalanan Dinas Dalam Negeri

b) Perjalanan Dinas Luar Negeri

c) Perjalanan Dinas Dalam Negeri Pihak ketiga dan Peserta On Job Training (OJT) Calon Pekerja

d) Perjalanan Dinas Luar Negeri Pihak Ketiga

Setelah mendapat kepastian/perintah untuk melakukan perjalanan dinas, untuk lebih lengkapnya Sekretaris melakukan kegiatan - kegiatan diantaranya :

- Membuat Jadwal Perjalanan/Itinerary (Daftar Lampiran 1)

- Menghubungi orang - orang/tempat yang akan dikunjungi dan menginformasikan bahwa Atasan/pekerja akan berkunjung ketempat tersebut.

- Memastikan apakah telah tersedia dari pihak pengundang untuk akomodasi dan transportasi.

- Menyiapkan bahan - bahan untuk perjalanan dinas tersebut. 
Sehubungan dengan hal tersebut, maka Sekretaris perlu melakukan hal - hal sebagai berikut :

\section{Tujuan Perjalanan Dinas}

Perjalanan dinas fungsi Turn Around Refinery dilakukan karena berbagai kepentingan, antara lain : mengikuti pendidikan dan pelatihan, kunjungan dinas, Seminar/Simposium, Penugasan Khusus dan berbagai kegiatan lainnya (Daftar Lampiran 2). Sekretaris mempersiapkan Jadwal Perjalanan/Itinerary yang diperlukan sesuai tujuan perjalanan dinas tersebut

\section{Pelaksanaan Waktu Perjalanan Dinas}

Disamping itu Seorang Sekretaris harus mengetahui peraturan - peraturan dan prosedur perjalanan dinas yang ada pada PT Pertamina (Persero). Pada PT Pertamina (Persero) Perjalanan Dinas menggunakan Sub Modul Travel Management-MySAP (Daftar Lampiran 3).

\section{Pemesanan Transportasi}

Pembagian kelas transportasi dalam peraturan perusahaan sebagai berikut :

Tabel 3-2. Fasilitas Transportasi

\begin{tabular}{|c|c|c|c|c|c|}
\hline \multirow{3}{*}{$\begin{array}{c}\text { KELOMPOK } \\
\text { PERJALANAN } \\
\text { DINAS } \\
1\end{array}$} & \multirow{2}{*}{$\begin{array}{l}\text { PEKERJA } \\
\text { (PEJABAT DEFINITIF) }\end{array}$} & \multicolumn{4}{|c|}{ SARANA TRANSPORTASI } \\
\hline & & \multirow{2}{*}{$\begin{array}{c}\begin{array}{c}\text { Pesawat } \\
\text { Terbang }\end{array} \\
\text { Bisnis }\end{array}$} & $\begin{array}{l}\text { Keret } \\
\text { a Apl }\end{array}$ & $\begin{array}{l}\text { Kapal } \\
\text { laut }\end{array}$ & $\begin{array}{l}\text { Bus, } \\
\text { dill }\end{array}$ \\
\hline & $\begin{array}{l}\text { L1 (Pejabat setingkat Senior Vice } \\
\text { President). Ka. SPI, Sekretaris Perseroan, } \\
\text { Chief Legal Counsel }\end{array}$ & & \multicolumn{3}{|c|}{ Kelas Tertinggi } \\
\hline 2 & $\begin{array}{l}\text { L2 (Pejabat setingkat VP/GM/setara); } \\
\text { PWT di bawah Direktur/Direktur Utama }\end{array}$ & Bisnis & \multicolumn{3}{|c|}{ Kelas Tertinggi } \\
\hline 3 & $\begin{array}{l}\text { L3 (Pejabat setingkat Manajer/ setara), } \\
\text { dan pekerja dengan golongan upah P1-P4 } \\
\text { non struktural }\end{array}$ & Ekonomi & \multicolumn{3}{|c|}{ Kelas Tertinggi } \\
\hline 4 & $\begin{array}{l}\text { Golongan Upah 5-1 dan PWT di bawah } \\
\text { SVPNP }\end{array}$ & Ekonomi & \multicolumn{3}{|c|}{ Kelas Tertinggi } \\
\hline 5 & $\begin{array}{l}\text { Golongan Upah 9-6, PWT di bawah } \\
\text { Manajer }\end{array}$ & Ekonomi & \multicolumn{3}{|c|}{ Kelas Tertinggi } \\
\hline 6 & $\begin{array}{l}\text { Golongan Upah 16-10, PWT di bawah } \\
\text { Asisten Manajer }\end{array}$ & Ekonomi & \multicolumn{3}{|c|}{ Kelas Tertinggi } \\
\hline
\end{tabular}

\begin{tabular}{|l|l|}
\hline \multicolumn{1}{|c|}{ JABATAN } & \multicolumn{1}{|c|}{ KELAS PESAWAT } \\
\hline Senior Vice President/setara & Kelas Bisnis ke semua negara \\
\hline VP/setara & Kelas Bisnis ke semua negara. \\
\hline Pejabat L3/Manager/setara & $\begin{array}{l}\text { Kelas Bisnis untuk penerbangan tanpa transit lebih dari } 4 \\
\text { jam, namun bila penerbangan kurang dari 4am jam } \\
\text { menggunakan fasilitas kelas ekonomi }\end{array}$ \\
\hline Pekerja lainnya & Kelas Ekonomi \\
\hline
\end{tabular}


Setelah melakukan pemesanan tiket pesawat kemudian mencetak e-ticket yang digunakan sebagai tiket sementara (Daftar Lampiran 4).

Pembayaran fasilitas transportasi menggunakan Corporate Card/Credit Card kepada maskapai yang telah menggunakan fasilitas on line, kantor perjalanan resmi atau maskapai penerbangan yang telah

Credit Card adalah sebentuk kartu plastic yang diterbitkan oleh bank penerbit sebagai alat pembayaran (Daftar Lampiran 5).

\section{Pemesanan Akomodasi}

Klasifiksi fasilitas akomodasi yang diberikan sesuai dengan aturan Perusahaan adalah :

Tabel 3-3. Fasilitas Akomodasi

\begin{tabular}{|c|c|c|c|c|c|c|}
\hline \multirow{2}{*}{$\begin{array}{l}\text { KELOMPOK } \\
\text { PERJALANAN } \\
\text { DINAS }\end{array}$} & \multirow{2}{*}{$\begin{array}{l}\text { PEKERJA } \\
\text { (PEJABAT DEFINITIF) }\end{array}$} & \multicolumn{4}{|c|}{$\begin{array}{l}\text { FASIUTAS } \\
\text { AKOMODASI } \\
\text { HOTEL BINTANG }\end{array}$} & \multirow[t]{2}{*}{ KETERANGAN } \\
\hline & & 5 & 4 & 3 & $<3$ & \\
\hline 1 & $\begin{array}{l}\text { L1 (Pejabat setingkat } \\
\text { Senior Vice President). Ka. } \\
\text { SPI. Sekretaris Perseroan, } \\
\text { Chief Legal Counsel }\end{array}$ & A & A & A & $\mathrm{C}_{1}$ & $\begin{array}{l}\text { KETERANGAN : } \\
\text { D - Kelas terendah } \\
C-\text { Setingkat dl atas D }\end{array}$ \\
\hline 2 & $\begin{array}{l}\text { L2 (Pejabat setingkat } \\
\text { VP/GM/setara): PWT di } \\
\text { bawah Direktur/Direktur } \\
\text { Utama }\end{array}$ & B & A & A & $\mathrm{C}_{1}$ & $\begin{array}{l}\text { B - Setingkat dl atas C } \\
\text { A - Setingkat di atas B } \\
\text { Hotel Elntang }<3\end{array}$ \\
\hline 3 & $\begin{array}{l}\text { L3 (Pejabat setingkat } \\
\text { Manajer/setara). dan } \\
\text { pekerja dg golongan upah } \\
\text { P1-P4 non struktural }\end{array}$ & c & B & A & $\mathrm{C}_{1}$ & $\begin{array}{l}\text { C1- Kelas tertinggl } \\
\text { D1- Setingkat dl bawan C1 }\end{array}$ \\
\hline 4 & $\begin{array}{l}\text { Golongan Upah } 5-1 \text { dan } \\
\text { PWT di bawah SVPNVP }\end{array}$ & D & c & B & $\mathrm{C}_{1}$ & \\
\hline 5 & $\begin{array}{l}\text { Golongan Upah 9-6. PWT } \\
\text { di bawwah Manajer }\end{array}$ & - & D & c & $\mathrm{C}_{1}$ & \\
\hline 6 & $\begin{array}{l}\text { Golongan Upah } 16-10 \text {. } \\
\text { PWT di bawah Manajer }\end{array}$ & - & - & D & D1 & \\
\hline
\end{tabular}

Diharapkan fasilitas akomodasi menggunakan hotel rujukan Perusahaan yang telah menggunakan Corporate Rate dengan menggunakan pembayaran Corporate Card/Credit Card (Daftar Lampiran 6).

Pada akhir pelaksanaan tugas masih ada satu tugas Sekretaris yaitu membantu membuat laporan perjalanan (deklarasi).

Adapun perhitungan dalam deklarasi tersebut diatur dalam beberapa ketentuan dan melampirkan data - data : SK PD-DN, Formulir Claim Deklasi, Laporan Perjalanan Dinas (Daftar Lampiran 7 \& 8).

Salah satu Laporan Perjalanan Dinas Dalam Negeri / klaim deklarasi biaya melampirkan sebagai berikut : 
- Akomodasi (Hotel)

- Transportasi (Tiket Pesawat, Tiket Kereta Api, Tiket Bis)

- Airport Tax

- Penggantian Transportasi

Tabel 3-4. Penggantian Biaya Transportasi

\begin{tabular}{|l|c|}
\hline Bandara & Rp. 250.000,- \\
\hline Stasiun KA/Pelabuhan Laut/Terminal & Rp. 200.000,- \\
\hline
\end{tabular}

Tabel. 3-5. Penggantian Biaya Transportasi Lokal

\begin{tabular}{|l|c|}
\hline Jabodetabek & Rp. 100.000,- \\
\hline Lainnya & Rp. 75.000,- \\
\hline
\end{tabular}

- Uang Makan

Uang Harian/Daily Allowance

- Miscellaneous

- Dokumen - dokumen yang mendukung klaim deklarasi tersebut.

Setelah Sekretaris membantu membuat deklarasi biaya perjalanan dinas dan melampirkan dokumen pendukung kemudian diserahkan kepada fungsi Keuangan untuk diverifikasi (Daftar Lampiran 9).

\section{G. Kesimpulan \& Saran}

\section{Kesimpulan}

Perjalanan dinas merupakan pelaksanaan tugas (Dalam Negeri dan Luar Negeri) yang diberikan oleh Perusahaan dalam kurun waktu tertentu, agar pekerjaan dapat berlangsung secara efisien dan efektif. Peran Sekretaris membantu Pimpinan/Pekerja dalam mempersiapkan pelaksanaan perjalanan dinas tersebut, sehingga pimpinan/pekerja dapat berkonsentrasi pada pelaksanaan tugas yang diberikan oleh Perusahaan. Perjalanan dinas fungsi Turnaround Refinery dilakukan karena berbagai kepentingan, antara lain : 
mengikuti pendidikan dan pelatihan, kunjungan dinas, Seminar/Simposium, Penugasan Khusus dan berbagai kegiatan lainnya.

\section{Saran}

Sekretaris harus mampu melakukan persiapan dan mengelola perjalanan dinas dengan baik sampai dengan selesainya perjalanan dinas tersebut. Sekretaris harus berperan aktif dalam perjalanan dinas tersebut dengan mengembangkan networking dengan Travel Agent, Pihak Hotel yang biasa dikunjungi atau yang telah bekerja sama dengan Perusahaan. Seorang Sekretaris harus mengetahui peraturan - peraturan dan prosedur perjalanan dinas yang ada pada PT Pertamina (Persero).

\section{DAFTAR PUSTAKA}

Kadarmo, Siwi. Ny. DR. 2001. Sekretaris dan Tugas- tugasnya. Jakarta : Nina Dinamika

Yadimah, Durotul. Dr. M.Pd. 2009. Pengembangan Sumber Daya Manusia Bidang Keahlian "Kesekretarisan Modern \& Administrasi Perkantoran". Bandung : Pustaka Setia

DON BOSCO, ASEKMA. 2010. Handbook of Modern Secretary : Panduan Sukses Sekretaris dalam Dunia Kerja Modern. Jakarta : PPm Manajemen

http://id.m.wikipedia.org/wiki/Sekretaris-Pengertian Sekretaris

http : // www.organisasi.org / 1970 / 01 / manajemen-sekretaris-pengertian-tugas - fungsi peran - syarat - tata kerja - dll.html

Tata Kerja Organisasi HR Development - HR Directorate PERTAMINA Perjalanan Dinas

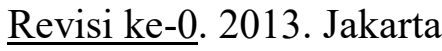

Ekawati, Ursula. 2004. Pedoman Lengkap Kesekretarisan Untuk Sekretaris dan Calon Sekretaris, Yogyakarta : Graha Ilmu

Sumarti, Hadi, Rumsar.i \& Dwiantara Lukas. 2000. Sekretaris Profesional. Yogyakarta : Kanisius

Hendarto, M.G, Hartiti \& Tulusharyono. F.X. Drs. MM. 2008. Menjadi SEKRETARIS PROFESIONAL, Jakarta : PPM 


\section{DAFTAR LAMPIRAN}

Lampiran 1 Jadwal Perjalanan/Itinerary

Lampiran 2 Memorandum/Perintah Perjalanan Dinas

Lampiran 3 Surat Keterangan Perjalanan Dinas

Lampiran 4 Electronic Ticket Receipt

Lampiran 5 Invoice Ticket - Travel Agent

Lampiran 6 Invoice Hotel

Lampiran 7 Formulir Perjalanan Dinas (Deklarasi)

Lampiran 8 Formulir Perjalanan System - My SAP

Lampiran 9 Tanda Terima Formulir Perjalanan Dinas (Deklarasi) 
